Rosse, Legal Med.; Casper, Forensic Med.; Elwell, Med. Juris.; Gerry, Forensic Med., Duverge, The prises de la Med.; Chitty, Forensic Med. 3. A uthorities on Hernim, specially.-H. O. Marcy, Operat. for Cure of
Hernia; Sir A. Cooper, Hernial Operations; Heaton, On Rupture; LawHernia; Sir A. Cooper, Hernial Operations; Heaton, On Rupture; Law Wood, Hernial Disease; Scarpa, Traité des Hernies.

Discussion.

Dr. I. N. Quimby, of New Jersey, agreed in the main with Dr. Manley, but claimed that there should be taken into account the individual's constitution, and that in cases of doubt in criminal violence the doubt should be solved against the criminal.

Dr. J. G. Kiernan, of Chicago, took issue with Dr. Quimby. The physician had nothing to do with the consequence. His duty was to state the facts found.

Dr. H. N. Moyer, of Chicago, cited a case of ventral hernia in which suit was to be brought for damages. He asked for diagnostic evidence in such cases, and as to the value of traumatism as a predisposing factor.

Dr. Manley, in closing, said that in the case of ventral herniæ predisposing factors existed.

"CEREBRAL ANATOMY."

Read in the Section of Neurology and Medical Jurisprudence, at the Forty-third annual meeting of the American Medical Association, held at Detroit, Mich., June, 1892. BY WILLIAM FULLER, M.D., OF GRAND RAPIDS, MICH.

Mr. Chairman and Gentlemen:-I have first to thank you for the permission to bring these specimens of anatomy before the Section, inasmuch as they are presented without previous notice, and is therefore a trespass upon your kindness.

I will next ask your indulgence, since I came here wholly unprepared to make any remarks upon them, for the reason that they are casts which are uncorrected by careful dissections which I hope to make in the near future as my time will permit. You will please to accept them as an illustration of what may be accomplished in this line of our work, which I think you will agree with me is important to the progress of our science, since until an exact anatomy of the central nervous system is acquired by the general practitioner so that he is able to make an intelligent post-mortem examination, and describe correctly the location and extent of lesions, our progress must necessarily be slow.

The clinical history of very important cases is neglected, and at present post-mortem examinations are negligently performed on account of the want of anatomical knowledge, in consequence of which we are sadly deficient of data upon which to formulate a rational theory of disease. Medical works on this subject, so far as my experience goes, are unsatisfactory and of little service. Theories are concocted and lines drawn on paper to illustrate the various centers and tracts, which being different in different books are utterly confusing, and even though these lines may be correct representations, it is so difficult to understand the meaning of the author, that the reader commonly gives it up in disgust, blaming his own incapacity, and holding the author in high regard as a man of exalted intellect. His cases are dispatched to the specialist, sent to a sanitarium, or allowed to perish unobserved at his door, and science has lost its opportunity. By means of these casts, which can be made to represent any part of the nervous system, the study becomes at once easy, more easy than from the fresh brain, because they can be turned over, handled, and the relations of parts considered by the student, and can be referred to while reading. I have been asked where I obtained so much material. I will tell you; I seldom have trouble in obtaining permission to open the head, because I promise, and am careful never to leave any deformity of the corpse, or get a drop of blood on the carpet when performing a post-mortem examination. Many opportunities for making post-mortem examination are lost through want of attention on our part to neatness and cleanliness, and to carelessness about producing deformity of the head. Much information is lost in post-mortems by a want of orderly method in the procedure, and more opportunities are lost through the exercise of levity and an air of heartlessness often assumed by the operator and those present. In accordance with the feelings of friends, and assimilated to the environments of the death chamber, gravity and the expression of that earnestness which is appropriate to the countenance of an inquirer is in my opinion in better taste. I speak of this because I think that we should be careful to cultivate the sources of our knowledge by removing all obstructions in the way of opportunity. Students should be well instructed in the methods of making post-mortems, and be examined in this branch of the art as in any other.

The method in which I study the central nervous system, is to commence with the spinal cord, and to notice as far as I am able, the analogies as I pass upward into the brain, which is to be considered as a continuation of the cord inverted, and the fibrous and vascular matter rearranged and adapted to the alteration.

\section{EVIDENCE OF THE SOMATIC ORIGIN OF INEBRIETY.}

Read in the Section of Neurology and Medical Jurisprudence, at the Forty-third annual meeting of the American Medical Association, beld in Detroit. Mich., June. 1892.

BY EUGENE S. TALBOT, M.D.,

OF CHICAGO, ILL.

Dr. Langdon Down first called the attention of the profession to the fact that contracted arches and high vaults were common among idiots. Later on Dr. W. W. Ireland contributed largely toward our knowledge of and interest in these deformities. Both of these gentlemen have charge of large English institutions for the feeble-minded; both of them, but more especially Dr. Down, believed that these deformities were pathognomonic of idiocy. Dr. Ballard contended that inasmuch as these deformities were very common among idiots and, as is frequently observed, idiots suck their thumbs, therefore the high vaults and contracted arches were caused by thumb sucking. Later on we shall see that these signs are no more proof of idiocy per se than that Hutchinson's teeth are characteristic of inherited syphilis. Congenital syphilis is a constitutional disease interfering with the development and growth of the body, hence the arrest of development of the crowns of the teeth. Now, any of the constitutional diseases, such as measles, scarlet fever, typhoid fever, etc., which also interfere with nutrition, will produce the same deformities of the teeth. After Down, Ireland and Ballard had made known the results of their researches on this subject, Drs. Kingsley, Stellwagon and White, of this country, made extensive investigations in our own institutions of idiocy, and reported that contracted arches and high vaults were, in their opinion, no more common among idiots than among their private patients. I had frequently ob- 
served in my own practice quite marked cases of deformities of the jaws and irregularities of the teeth, hence you will observe my analogy to the Hutchinson teeth. That these deformities of the jaws and irregularities of the teeth were found to be nearly, if not quite, as frequent among apparently healthy individuals as among idiots, led me about twelve years ago to take up this particular line of study, with a view of ascertaining, if possible, the cause of these peculiar deformities.

I will not weary you with a recital of the different theories advanced as causes of these deformities, but as briefly as possible will give you the results of my own investigations. You are all aware that the main feature in idiocy is arrest of development of brain tissue; that the growth of the brain is greater between birth and the seventh year, than during any other period in life. After this period the substance of the brain and the different tissues of the body grow rapidly. If the brain be a healthy one, we would naturally expect to find all the tissues of the body developing in a normal, healthy manner. On the other hand, if the brain be diseased or arrested in its development, we would expect to find the tissues of the body arrested in their development. Reasoning from this standpoint, we observe that the different structures which go to make up the body of prepared to state. The shape and character of the deformity depends entirely upon the order of the eruption of the teeth. Thus if a cuspid tooth is the last to erupt, the anterior part of the jaw becomes contracted, the incisors are thrown forward and the V-shaped arch is produced. If, on the other hand, the cuspid erupts before the bicuspid, the saddleshaped arch will be formed. The cause of the deformity is a local one, depending upon a small jaw. There is, however, another cause for the small jaw, that must not be lost sight of, and which is not eonstitutional but local in its makeup, viz.: If the temporary molar decays early, or is extracted before the proper time, the first permanent molar will advance forward and fill the space made vacant by the removal of the first temporary molar. This condition must be taken into consideration in making up our diagnosis. I only give the cause in a general way for want of time, but each variety is explained in my work upon "Irregularities of the Teeth." Having thus found the cause, the question naturally arises: "Shall we not find as large a percentage of defective among inebriates as other neurotics?" .I have therefore examined the mouths of all of these classes. I will now give you the results of my investigations, taking them in the order in which they were made.

TABLE OF DEFORMITIES OF THE JAWS OF THE DEGENERATES.

\begin{tabular}{|c|c|c|c|c|c|c|c|c|c|c|}
\hline & No. & Normal. & $\begin{array}{c}\text { Large } \\
\text { Jaw. }\end{array}$ & $\begin{array}{c}\text { High } \\
\text { Vault. }\end{array}$ & $\begin{array}{l}V- \\
\text { Shaped } \\
\text { Areh. }\end{array}$ & $\begin{array}{l}\text { Partial } \\
\text { V- } \\
\text { Shaped } \\
\text { Arch. }\end{array}$ & $\mid \begin{array}{c}\text { Semi } \\
\text { V- } \\
\text { Shaped } \\
\text { Arch. }\end{array}$ & $\begin{array}{c}\text { Saddle } \\
\text { Arch. }\end{array}$ & $\begin{array}{l}\text { Partial } \\
\text { Saddle } \\
\text { Arch. }\end{array}$ & $\begin{array}{l}\text { Semi- } \\
\text { Saddle } \\
\text { Arch. }\end{array}$ \\
\hline $\begin{array}{l}\text { Idiots } \\
\text { Deaf and Dumb } \\
\text { Blind } \\
\text { Insane } \\
\text { Crimind } \\
\text { *Inebriates } \\
\text { Normal }\end{array}$ & $\begin{array}{r}1,977 \\
1,935 \\
207 \\
700 \\
477 \\
514 \\
1,000\end{array}$ & $\begin{array}{l}55.3 \\
45.3 \\
50.7 \\
62.0 \\
36.06 \\
25.04 \\
78 .\end{array}$ & $\begin{array}{c}7.6 \\
15.7 \\
7.7 \\
18 . \\
15.72 \\
6.4 \\
1.9\end{array}$ & $\begin{array}{l}16 . \\
21.7 \\
18.3 \\
44 . \\
14.67 \\
59.5 \\
5.6\end{array}$ & $\begin{array}{c}6.5 \\
8.7 \\
3.3 \\
26 . \\
2.70 \\
1.5 \\
1.1\end{array}$ & $\begin{array}{c}11.9 \\
9.9 \\
4.3 \\
47.00 \\
16.56 \\
24.4 \\
6.1\end{array}$ & 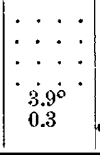 & $\begin{array}{c}10.4 \\
10.4 \\
5.3 \\
12 . \\
12.36 \\
9.3 \\
3.3 \\
\end{array}$ & 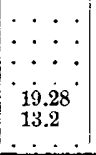 & $\begin{array}{l}\therefore \cdots \\
\therefore \therefore \\
\dot{5} .08 \\
7.7\end{array}$ \\
\hline
\end{tabular}

* The examination of inebriates was made in the Keeley Institute, Dwight, Ill.; the Inebriates Home, Ft. Hamilton, N. Y.; Washingtonian Home, Chicago; Washingtonian Home, Boston; and Dr. Crothers' Institute, Hurtford, Conn.

the idiot are very markedly deformed, and excessive development and arrest of development of tissue are frequently noticed. No other tissues of the body receive so marked an impression as the osseous system. Hence we observe excessive and arrested development of the jaws very frequently.

We noticed that the brain adds but little to its size after the seventh year; irregularities of the jaws and teeth are rarely if ever seen before that period. In other words, deformities are never observed with the first set of teeth. Now it is a singular fact that the first permanent molar makes its appearance at the sixth year. The superior maxilla and the bones of the cranium cease to develop in these cases at that period.

The second set of teeth requires a jaw one-third larger than does the first set, hence in those cases where the superior maxilla and bones of the cranium cease to develop at an early age, there is not sufficient room to accommodate them.

Contracted jaws and irregularities of the teeth always take place between the seventh and twelfth year, and if from any cause arrest of development due to defective brain should result, contracted jaws and irregularities of the teeth would take place at that period. The high vault is modern architecture; it is never seen in ancient skulls, and is more common in this country than in any other. It is always or nearly always noticed in defective individuals, neurotics, etc. Just how it is developed I am not
It will be observed, that there is a larger percentage of deformities among the inebriates than among any other defective class.

These deformities, however, are not so pronounced as those found among the idiots and criminal classes. The large percentage of deformities and high vaults indicate a strong neurotic tendency early in life, even before the seventh year. Finally, if the child from the seventh to the twelfth year has arrested development of the superior maxilla, and possesses constitutional irregularities of the teeth and a high vault, we can almost invariably say that the individual will become, not always an idiot, but a genius in some one direction or an idiot, a deaf, dumb, blind, insane, criminal, an extreme egotist, excessive tobacco user, or an inebriate-all of these conditions coming under the head of degenerates, or neurotics. In making a diagnosis of any one of these classes of individuals mentioned, we should always take into account these three conditions of deformities of the jaws, viz.: arrest of development of the superior maxilla, constitutional irregularities of the teeth and high vaults.

\section{Discussion.}

Dr. J. G. Kiernan, Chicago, Ill.:-In a small proportion of inebriates the essential factor is a condition of degeneracy pointed out by Benjamin Rush several decades ago. It was undoubtedly true that a large number of the neuroses and psychoses occurring in these degenerate individuals had a tendency to assume a periodical type. The nerves themselves had periodicity of function. A distinction should be made between three classes. First, there is a vice class 
among inebriates; second, there is an inebriate class in whom the condition is the result of constitutional defect, but it does not assume a periodical type; third, there are many cases of this periodical type of degeneracy which are a manifestation of the periodical psychoses.

With regard to Dr. Dewey's paper, the fact was noticeable that the majority of cases had associated with them other factors in addition to the hereditary element and drink habit tending to produce insanity, as the morphine habit. The sudden stoppage of morphine in a neurotic individual might bring about insanity.

Dr. H. N. Moyer, of Chicago, considered Dr. Crothers paper an exceedingly valuable contribution. It showed that inebriety obeys the law of many other nervous diseases. Most nervous diseases in a certain sense were periodical. A nerve never pains continually in neuralgia, and the pain is never equally severe at all times. There are periods of remission.

The matter of Dr. Talbot's paper should not be lost sight of, the somatic origin of inebriety as demonstrated in idiocy and other allied affections which Dr. Kiernan had classed among the degenerate types.

In regard to Dr. Dewey's paper, he thought the author had dealt too leniently with Dr. Keeley. He believed the only gold in the Keeley treatment came from the pockets of credulous patients. An analysis of the remedy as sent out for home treatment had been made in Philadelphia by an able chemist, and nothing of importance was found in the "shot," as it is called. It contains no chloride of gold and sodium, and no strychnia, simply an organic compound, of no marked physiological activity. The "dope" was a mixture of tineture of cinchona and tincture of gentian. It had been his misfortune to have sent four patients to Dwight, and these four had relapsed. The speaker believed the only effect of the Keeley treatment was purely one of hypnotism, to use a term that was much abused. The hypnotism, however, was not applied as physicians commonly use it in producing hypnotic sleep, such as fixing the attention on a distant point, or other means of sensory perception. The hypnotism and suggestion was bound up with the hypodermic syringe, which was used several times a day, and in the association of large numbers for treatment, and the persistence with which they were told that they were cured.

The paper was further diseussed by Drs. McClelland and Green, of Michigan, Dewey, Talbot and Crothers.

\section{THE LAW OF PERIODICITY IN INEBRIETY.}

Read before the Section of Neurology and Medical Jurisprudence, at the Forty-third Annual Meeting of the American Medical Association, held at Detroit, Mich., June, 1892

BY T. D. CROTHERS, M.D.

OF HART FORD, CONN.

EUPT. WALNUT LODGE HOSPITAL, EDITOR JOURNAL INEBRIETY, ETC., ETC.

The alternation and periodicity of the functions of the brain and nervous system have not been fully studied. Periods of inactivity as in sleep and wakefulness for a definite time, the rise and fall of temperature, increase in heart pulsation and cardiac pressure, the nutrient and reproductive periods, are all common physiological periodicities. This same mysterious alternation appears in the diseases and degenerations of the brain and nervous system.

The neuralgias, migraines and epilepsies are familiar illustrations. In insanity the folie circulaire is equally noticeable.

This rise and fall of nerve functions, together with halts, alternations and relapses in disease, suggest a field of laws and forces that are largely unknown.

The inebriate who drinks to great excess at distinct intervals and abstains totally during the intervening time, is a type of the neurotic character of these strange cycle degenerations.

Literally, and in appearance these cases represent in one person, a type of exemplary living, and a state of alcoholic frenzy, with mental and moral degeneration-recurring within fixed intervals of time.
At one period the victim is a rigid moralist and strict abstainer and by word and example is often a temperance lecturer of an aggressive type whose views are emphatic and earnest. Later, he is secretly and openly an excessive drinker and a low intriguerdisplaying the most opposite traits of character and conduct.

Yet the public accept his theories of inebriety and its remedies, and assume his experience as knowledge. not possible to others.

Unlike any other victim of disease, his judgment is held in higher esteem, and his views are considered as authority on this topic.

Some general statistics indicate that over 60 per cent. of all inebriates are of this periodic character.

The length of the free interval varies widely from one week to two or more years, and in some cases recurs at distinct intervals not varying more than a few hours.

In others this free interval is very irregular- ap. parently depending on unknown conditions of environment. In others it follows certain functional derangements and disturbances of nerve and brain health.

In certain cases it appears as mysteriously as a flash of electricity in a cloudless sky, with no premonition or hint, and each attack comes on in an. equally mysterious way.

The clinical history of these cases reveal several distinct classes, with widely varying symptoms and conditions.

One of the most prominent groups I have met are the insane impulsive periodics. The free interval varies widely. The drink craze comes on abruptly when least expected. Thus, at some unexpected moment when his presence and judgment are most essential to success, and when the drink craze may be almost fatal, he will fall.

As an illustration, on the eve of marriage, or some. social, political, or literary triumph, or business success, this delirium appears.

He will disappear and conceal his condition, or boldly display his insanity in opposition to all advice or entreaty. Then suddenly realize his condition and make a great effort to recover.

Intense sorrow and grief, coupled with explanations, prevarications and earnest efforts to repair the losses will follow.

Often he will ascribe his recovery to some means. or remedy taken at the last moment and defend it with delirious faith and energy.

$\mathrm{He}$ is often unable to give any rational idea of the motive or reasoning which preceded the drink craze.

His memory is always vague as to the nature of his acts, and although events may be clear, the higher consciousness is cloudy.

The reason and judgment seem to be suddenly arrested by some morbid impulse which palsies every other consideration.

These paroxysms come without any apparent premonition, and are a surprise to the victim and his. friends.

The drink thirst continues up to a certain point and then dies out suddenly.

The character of the acts in this delirium vary from maudlin religiosity to wild aggressiveness-and through all degrees and forms of insane acts.

Men in this state will display delirious zeal for thetemperance cause and be very prominent in revival 